\title{
Simulation of Trough Withering of Tea using One Dimensional Heat and Mass Transfer Finite Difference Model
}

\author{
W.S. Botheju*, K.S.P. Amarathunge ${ }^{1}$ and I.S.B. Abeysinghe ${ }^{2}$ \\ Postgraduate Institute of Agriculture \\ University of Peradeniya \\ Sri Lanka
}

\begin{abstract}
One-dimensional heat and mass transfer mathematical model was developed to simulate moisture content of tea leaves during trough withering. Model solutions were approached using finite difference method with appropriate boundary conditions. A computer program written in QBASIC was used to calculate the real time moisture content of tea leaves and other psychometric parameters of conditioned air during withering. Four experiments were performed using commercial type of withering trough to validate the developed model. Leaf samples were drawn from top, middle and bottom layers of the leaf bed in the trough for one-hour time interval for $12 \mathrm{~h}$ of the test period. Simulated moisture data calculated by the program was compared with the experimental data. Time and space increments of the model were chosen minimizing the estimation error of moisture content. Results showed that the experimental and simulated moisture data were in close agreement for top, middle and bottom layers of the withering trough with standard errors in the range of 0.2940-1.2872, 0.7148-1.1025 and 0.7106-4.5478, respectively on percent wet basis.
\end{abstract}

Keywords: Fresh tea leaves, one dimensional heat and mass transfer model, withering trough

\section{INTRODUCTION}

Tea is a popular beverage throughout the world because of its astringent taste and inherent flavor characteristics. The primary goal of tea industry is to supply the market with safe and quality product. Quality of made tea is directly influenced by the taste and aroma of tea liquor. Good manufacturing practices are necessary to process good quality tea. Black tea processing involves five major unit operations namely withering, rolling, fermentation, drying and grading. Withering is very important in black tea processing because it consumes the highest amount of electrical energy and fairly large amount of thermal energy. In addition, uniformly withered tea leaves are essential to produce good quality end product.

Initial moisture content of fresh tea leaves varies from $70-83 \%$ w.b. depending on the climatic condition, weather pattern and the type of tea cultivar (Samarawera, 1986). Orthodox is the most popular black tea processing method in Sri Lanka. Initial moisture content of tea leaves is reduced to $55 \%$ w.b. within $12-16 \mathrm{~h}$ during withering in Orthodox method. The appearance of tea shoots at the final stage of withering has pale green color and

To whom correspondence should be addressed: wsbotheju@yahoo.com

Department of Agricultural Engineering, Faculty of Agriculture, University of Peradeniya, Sri Lanka

Tea Research Institute, Talawakelle, Sri Lanka 
flaccid with unbreakable stems. A person with good experience can identify the correct stage of withering. Therefore determining correct withering stage is merely depends on the personal experience. The moisture content of tea leaves in withering determines the wither percentage. Therefore different types of meters were developed to determine the moisture content of leaf samples. The standard method of determining moisture content of tea leaves is using air oven for $6 \mathrm{~h}$ at $103^{\circ} \mathrm{C}$ (ISO 1568, 1980). A method was later developed to determine moisture content of withered leaf within $10 \mathrm{~min}$ period using a microwave oven (Mohamed et al., 2003). These methods are however not practicable to determine the real time moisture content of tea leaves.

Different mathematical models with one or two dimensional heat and mass transfer equations were used to predict real time temperature, moisture content etc. in various food products (Muir, et al., 1980 and Murata et al., 1996). The numerical solutions of these models can be obtained by finite difference method (Yacink et al., 1975). In the literature, it is difficult to find any developed mathematical approach to determine moisture content of tea leaves during withering.

In this study, one-dimensional heat and mass transfer model was developed for tea withering and the numerical solutions of the model were approached by finite difference method. The model was validated using a commercial type of withering trough.

\section{METHODOLOGY}

\section{Model development and numerical solutions}

Heat and mass transfer phenomenon between conditioned air and tea leaf surface was considered in developing the model for a deep bed of tea leaves in the trough. Both the thermal and the flow properties of air together with geometry of the system are directly affect the heat and mass transfer coefficients. A set of differential equations was used to describe the withering process of deep bed of tea leaves under the following assumptions.

1. Withering process was an adiabatic and reversible.

2. Heat transfer by conduction between leaves was negligible.

3. There was no hysteresis effect between adsorption and desorption isotherms of tea leaves.

4. The temperature and relative humidity distribution of air in the leaf bed were uniform in horizontal direction, i.e. heat and moisture flow in the horizontal direction was assumed negligible.

Based on the assumptions, only the vertical component of the airflow was considered in model development. Therefore the problem was treated as one-dimensional.

\section{Mathematical model development for trough withering}

The model contains differential equations for calculating leaf temperature, leaf moisture, enthalpy and absolute humidity of air at an arbitrary point in the deep bed. Leaf bed was divided into finite number of thin layers in modeling (Fig. 1). Air enters into the bed of leaf from the bottom and flows across the bed and leaves at the top of the bed. 
Following equations were used to model the withering process of tea leaves.

The drying rate of fresh tea leaves is calculated using the following differential equation (Eq. $1)$.

$$
\frac{d M}{d t}=-k\left(M-M_{e}\right)
$$

Where $k$ is the drying coefficient of fresh tea leaves and was calculated using the Eq. 2 with temperature and relative humidity of air (Botheju et al., 2008).

$$
k=f_{1} \exp \left(\frac{f_{2} h^{3}+f_{3} h^{2}+f_{4} h+f_{5}}{T}\right)
$$

Where;

$$
\begin{array}{ll}
f_{1}= & 728705.0448 \\
f_{2}= & 219.5551 \\
f_{3}= & -1998.3448 \\
f_{4}= & 1146.5436 \\
f_{5}= & -6121.8327
\end{array}
$$

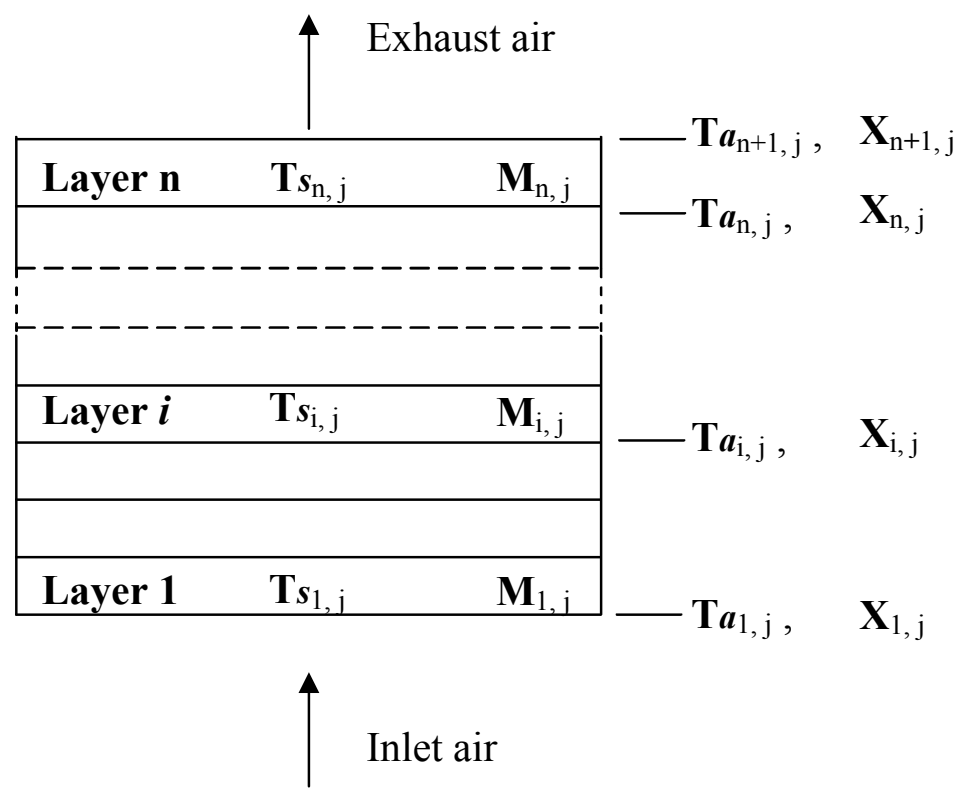

\section{Fig. 1. Finite difference scheme}

$M_{e}$, the equilibrium moisture content in Eq. 1 was determined by Oswin isotherm (Eq. 3). Constants in the equation were calculated for fresh tea leaves. 


$$
M_{e}=\left(55.4994-0.1272 T_{a}\right)\left[\frac{h}{1-h}\right]^{0.2275}
$$

Finite difference solution of the Eq. 1 with initial conditions of $M=M_{0}$ to calculate the moisture content of $i^{\text {th }}$ layer, $M_{i}$ of withering tea leaves is given by equation (Eq. 4).

$$
M_{i, j+1}=M_{i, j}-k\left(M_{i, j}-M_{e i, j}\right) \Delta t
$$

Leaf temperature at the beginning of withering is very close to wet bulb temperature of air. Murata, et al. 1996 has used Eq. 5 for calculating the material temperature in deep bed simulation and the same equation was used in calculating the leaf temperature in withering.

$$
\frac{\partial T_{s}}{\partial t}=\left(\frac{h_{a}}{C_{p s} \rho_{s}}\right)\left(T_{a}-T_{s}\right)-\left(\frac{k q}{C_{p s}}\right) \frac{\left(M-M_{e}\right)}{100}
$$

Where $h_{a}$ is the convective heat transfer coefficient and was calculated using Eq. 6 (Botheju, 2009).

$$
h_{a}=0.0025 G
$$

The heat of vaporization of water in tea leaves decreases with increasing moisture content in the desorption process. Rearranging the Clausius-Clapeyron equation (Moore, 1962) gives the change of saturated vapor pressure with $q$ (Eq. 7).

$$
q=T\left(V_{g}-V_{l}\right) \frac{d P_{s t}}{d T}
$$

The term $\left(V_{g}-V_{l}\right)$ was calculated by Eq. 8 .

$$
V_{g}-V_{l}=R_{w} \frac{T}{p}-0.001
$$

Where $R_{w}=0.4619 \mathrm{~kJ} / \mathrm{kg} \mathrm{K}$ (Cengel and Boles, 1989).

The vapor pressure in tea leaves, $\boldsymbol{P}_{\boldsymbol{s} t}$ was calculated using Eq. 9.

$$
P_{s t}=h P_{s}
$$

$d P_{s t} / d T$ in Eq. 7 was obtained by differentiating Eq. 9 with respect to $T$ given by Eq. 10 ,

$$
\frac{d P_{s t}}{d T}=\frac{d h}{d T} P_{s}+\frac{d P_{s}}{d T} h
$$

The term $d h / d T$ can be calculated by differentiating the Eq. 3 with respect to $T$. $d P_{s} / d T$ is calculated using Eq. 11 which gives the saturated vapor pressure of air $P_{s}$ (Bolton, 1980). 


$$
P_{s}=0.61078 \exp \left(\frac{T_{c}}{\left(T_{c}+238.3\right)} * 17.2694\right)
$$

Substituting all the terms into Eq. 7, $q$ can be calculated.

The bulk density of green leaves $\left(\rho_{s}\right)$ of the trough bed varied depending on the quantity of leaf received to the factory. When withering is progressed, $\rho_{s}$ was significantly varied with time and followed Eq.12. The bulk density, $\rho_{s}$ of green leaves of the trough bed also varies depending on the quantity of leaf loaded to the trough.

$$
\rho_{s}=W_{t} / V_{t}
$$

$$
\text { Where } W_{t}=\left(100-M_{o}\right)\left[\frac{W}{\left(100-M_{w b}\right)}\right]
$$

Where $W_{t}$ is the weight of leaves loaded to the trough and $V_{t}$ is the volume of the trough.

The specific heat capacity $\left(C_{\mathrm{ps}}\right)$ of tea leaves was determined using Eq. 13 (Siebel, 1892).

$$
C_{p s}=0.827+3.348 M_{d(w b)}
$$

Finite difference solution of Eq. 5 to calculate the leaf temperature could be given as follows (Eq. 14).

$$
T_{s i, j+1}=T_{s i, j}+\left(\frac{h_{a}}{C_{p s} \rho_{s}}\right)\left(T_{a i, j}-T_{s i, j}\right) \Delta t-\left(\frac{k q}{C_{p s}}\right) \frac{\left(M_{i, j}-M_{e i, j}\right)}{100} \Delta t
$$

The absolute humidity of air in the leaf bed was calculated by Eq. 15 (Murata et al., 1996).

$$
\begin{aligned}
& \frac{\partial X}{\partial y}=-K_{2}\left(M-M_{e}\right) / 100 \\
& \text { Where; } \quad K_{2}=\rho_{s} \frac{k}{G} \\
& G=V \rho_{a} \\
& \rho_{a}=\frac{353.3}{T_{a}}
\end{aligned}
$$


Numerical solution of the Eq. 15 to calculate absolute humidity (kg-water/kg dry air) of air is in the following form (Eq. 19);

$$
X_{i+1, j}=X_{i, j}+K_{2}\left(M_{i, j}-M_{e i, j}\right) \Delta l
$$

The governing equation to calculate enthalpy of the conditioned air is given by Eq. 20 (Murata et al., 1996).

$$
\frac{\partial I}{\partial y}=\left(\sigma K_{2}\right)\left(M-M_{e}\right)-\left(\frac{h_{a}}{G}\right)\left(T_{a}-T_{s}\right)
$$

Where $\sigma$ is very close to the latent heat of vaporization of pure water.

The solution of the Eq. 20 in the finite difference form could be written as Eq. 21:

$$
I_{i+1, j}=I_{i, j}+\left(\sigma K_{2}\right)\left(M_{i, j}-M_{e i, j}\right) \Delta l-\left(\frac{h_{a}}{G}\right)\left(T_{a i, j}-T_{s i, j}\right) \Delta l
$$

Air temperature $\left(T_{a}\right)$ changes across the leaf bed was calculated using Eq. 22 (Murata et al., 1996)

$$
T_{a}=\frac{I+0.026-\sigma X}{C_{p a}+C_{p w} X}
$$

The relative humidity of air $(r h)$ leaving the layer was calculated by Eq. 23 .

$$
r h=\frac{p}{P_{s}}
$$

Where ;

$$
p=\frac{P X}{0.622+X}
$$

Where $P=101.325 \mathrm{kPa}$. Saturated vapor pressure $P_{s}$ was calculated using Eq. 11 .

Two empirical relationships were developed for leaf bed height and volume flow rate of air against moisture content since those two variables vary during withering. Both variables are needed to calculate enthalpy and absolute humidity of air.

Horizontal thin layers were subjected to uniform conditions of air throughout the selected time interval, $\Delta t$. Exhaust air conditions from one layer were taken as input conditions to the layer immediately above. Knowing the inlet air conditions at any given layer and the initial layer moisture content, final air conditions and leaf moisture content were calculated at the end of $\Delta t$. The procedure was repeated for each layer in the bed at a given time interval. 
In the model, element thickness $(\Delta l)$ varied while withering was progressed. Developed empirical relationship for leaf bed height was incorporated to the model and $\Delta t$ was taken as $5.5 \mathrm{~s}$. withering

$$
\text { Initial conditions } \quad \begin{aligned}
T_{\mathrm{s} i, j} & =\text { Wet bulb temperature } \\
M_{i, j} & =\text { Initial moisture content of tea leaves }
\end{aligned}
$$

$\begin{array}{ll}\text { Boundary conditions } & T_{a i, j}=\text { Air temperature measured during } \\ \text { withering } & X_{i, j}=\text { Relative humidity of air during withering }\end{array}$

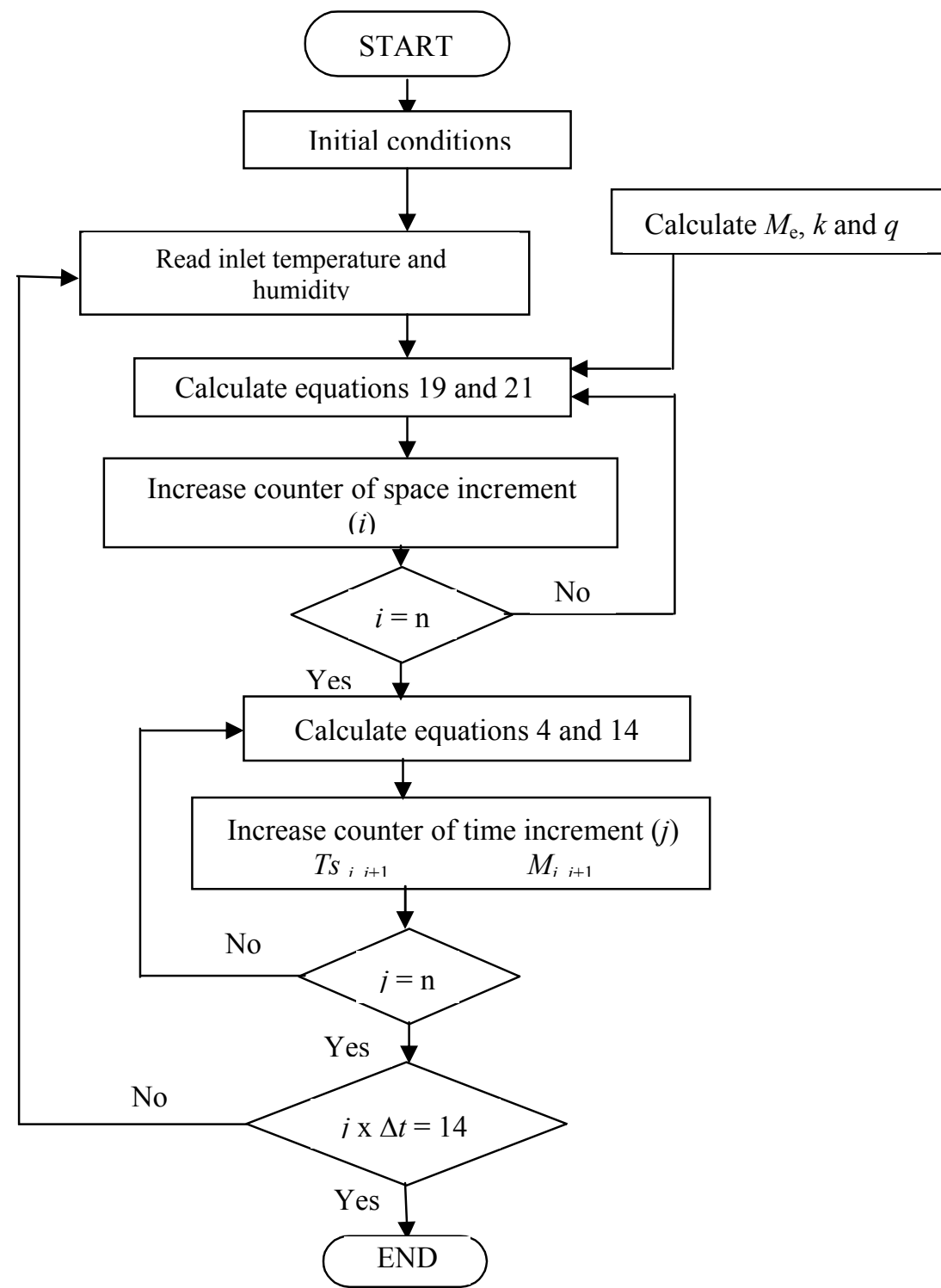

Fig. 2. Program flow chart for predicting moisture content of tea leaves during withering 
QBASIC program was written based on the flow chart shown in Fig. 2. Velocity of air decreased during the withering process.

\section{Model validation}

Tea leaves plucked from St. Coombs estate in the morning were transported to the tea factory and weighed at $\pm 1 \mathrm{~kg}$ accuracy. The commercial scale withering trough with the area of 28.5 $\mathrm{m}^{2}$ was loaded with $800 \mathrm{~kg}$ of tea leaves. Temperature and RH sensors coupled with PCbased data acquisition system were fixed at three positions in the trough chamber to measure temperature and $\mathrm{RH}$ of air (Fig. 3) entering to the trough chamber during withering. Random sampling was conducted from front, center and rear end of the trough bed before switching on the trough fan to determine the initial leaf moisture. Fan was switched on and leaves were immediately loosened. The operation of data acquisition system was commenced simultaneously to read the $\mathrm{RH}$ and temperature of air in the plenum chamber throughout withering. Wet bulb temperature of air in the chamber was also recorded.

(2)

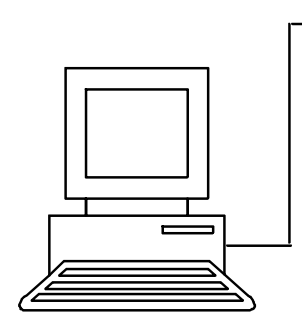

(3)

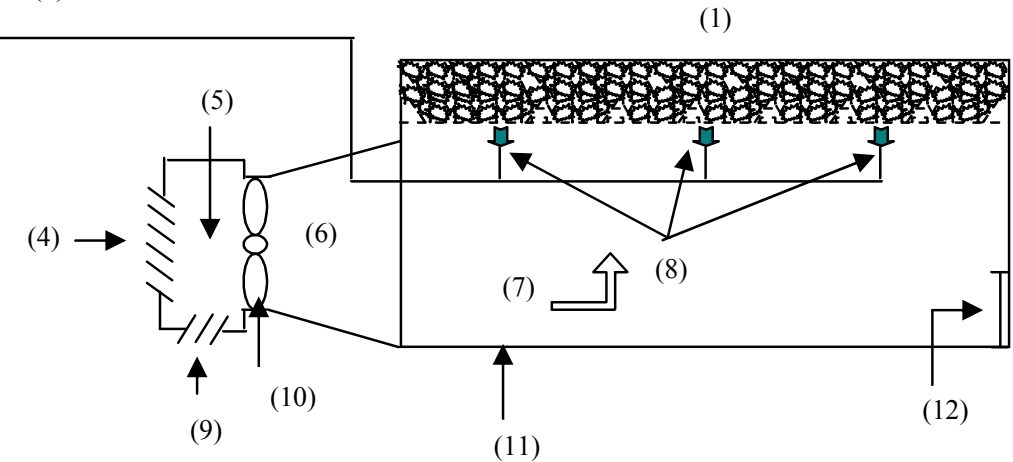

$\begin{array}{ll}\text { (7) } & \text { Airflow path } \\ \text { (8) } & \text { Temperature and RH sensors } \\ \text { (9) } & \text { Warm air } \\ \text { (10) } & \text { Axial fan } \\ \text { (11) } & \text { Plenum chamber } \\ \text { (12) } & \text { Gable door }\end{array}$

(1) Leaf bed

(2) Wire connection

(3) Data acquisition system

(4) Cold air

(5) Mixing chamber

(6) Transformation duct

Fig. 3. Schematic diagram of the experimental trough withering set up

After 30 min of switching on the fan, 18 samples were drawn from top, middle and bottom layers of the leaf bed along the length of trough and immediately put them into a polythene bag and sealed. Known quantity of sample $(50 \mathrm{~g})$ was then drawn from each bag to determine the moisture content in three different layers using the air oven method $\left(103^{\circ} \mathrm{C}\right.$ for $6 \mathrm{~h})$.

The sampling procedure was repeated at one-hour interval throughout withering. Initial moisture content and wet bulb temperature were input to the QBASIC program. Air temperature and $\mathrm{RH}$ measured from the sensors were also used in the program as boundary values. Moisture contents of top, middle and bottom layers and the average moisture content calculated by the model were compared with the experimental moisture data. 


\section{RESULTS AND DISCUSSION}

The heat of vaporization $(q)$ of water in tea leaves was calculated using the Eq. 7. The graph between $q$ and moisture content of tea leaves at four different temperatures are presented in Fig. 4. It shows that latent heat of vaporization decreases with increasing of the moisture content. The value of $q$ approached the latent heat of free water at the moisture content above $40 \%$ d.b. Decreasing moisture content below $20 \%$ d.b. latent heat of vaporization increased almost exponentially.

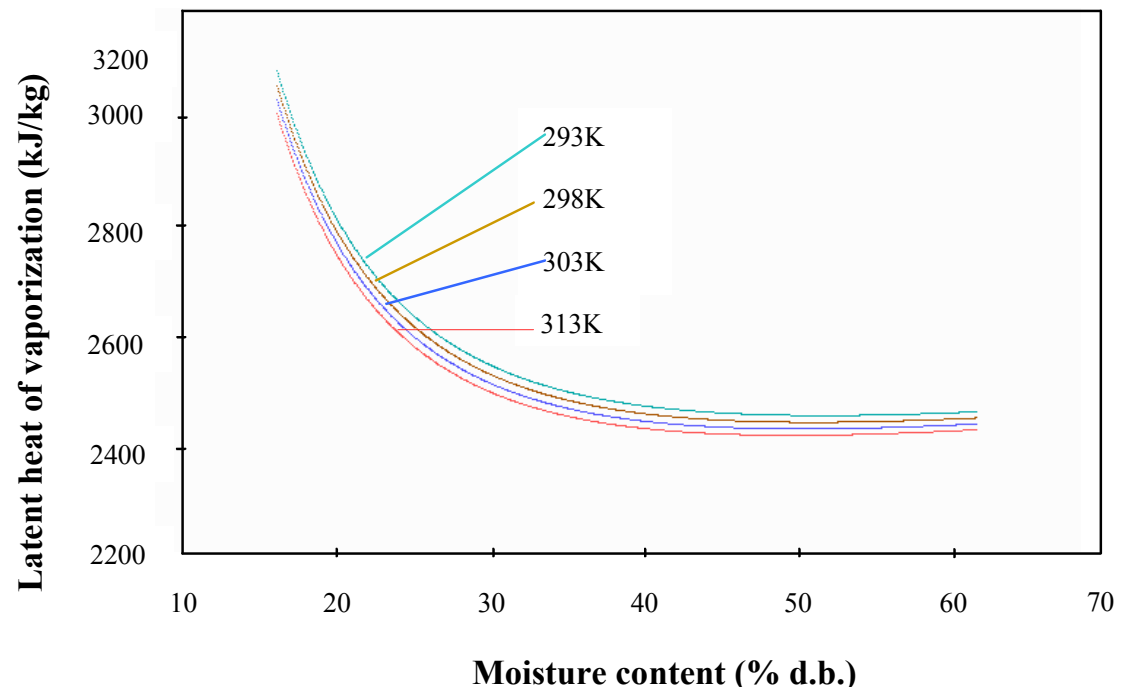

Fig. 4. Heat of vaporization of water in tea leaves at four different temperatures and moisture contents

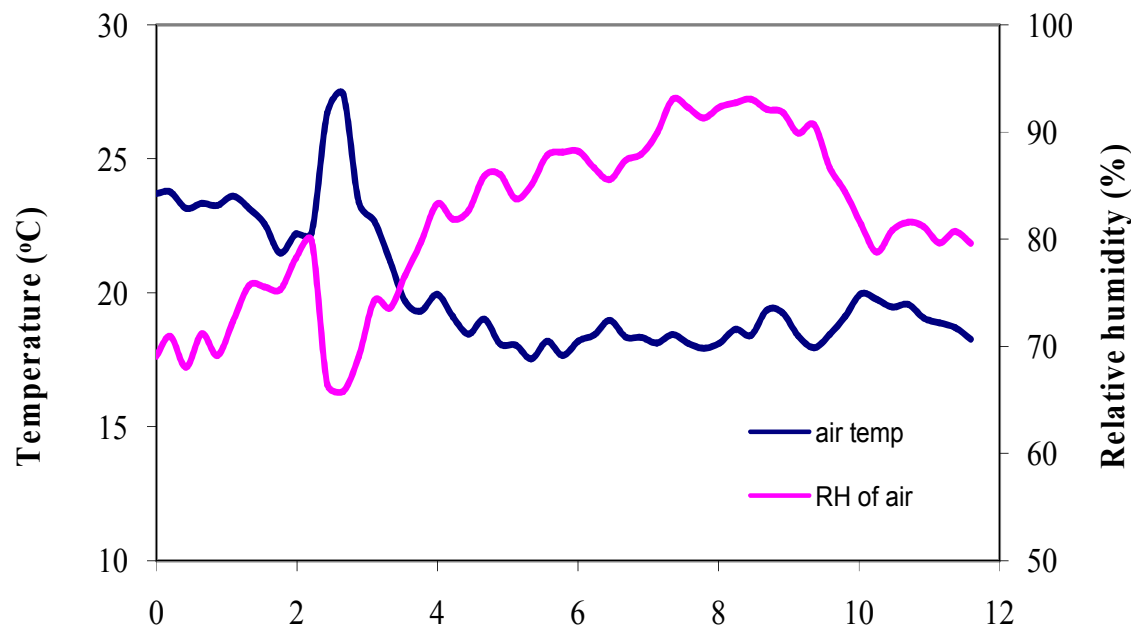

Time (h)

Fig. 5. Variation of temperature and RH of air during the test period of withering in experiment (I) 
(I)

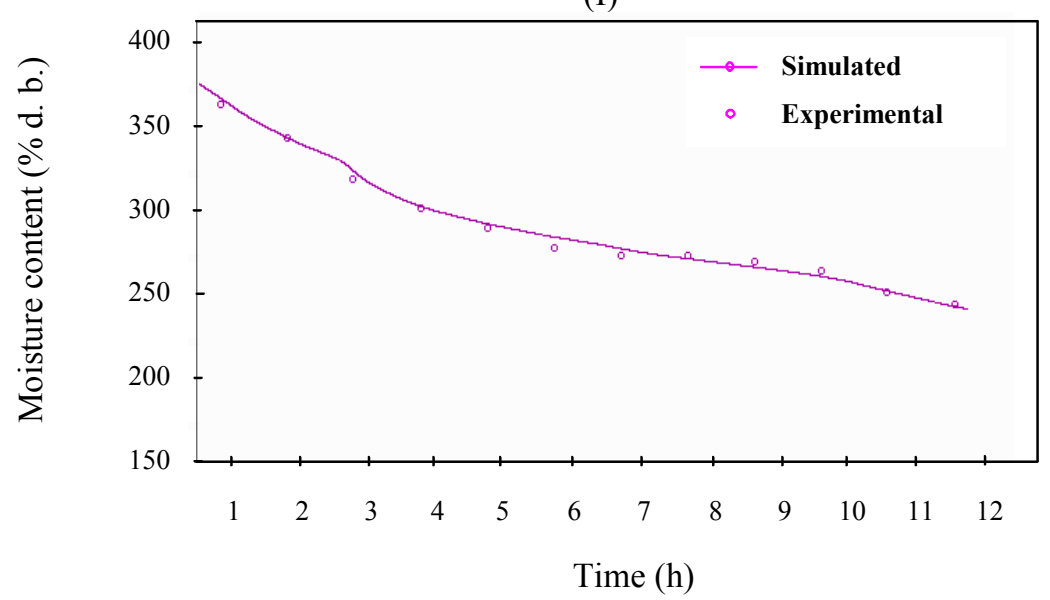

(III)

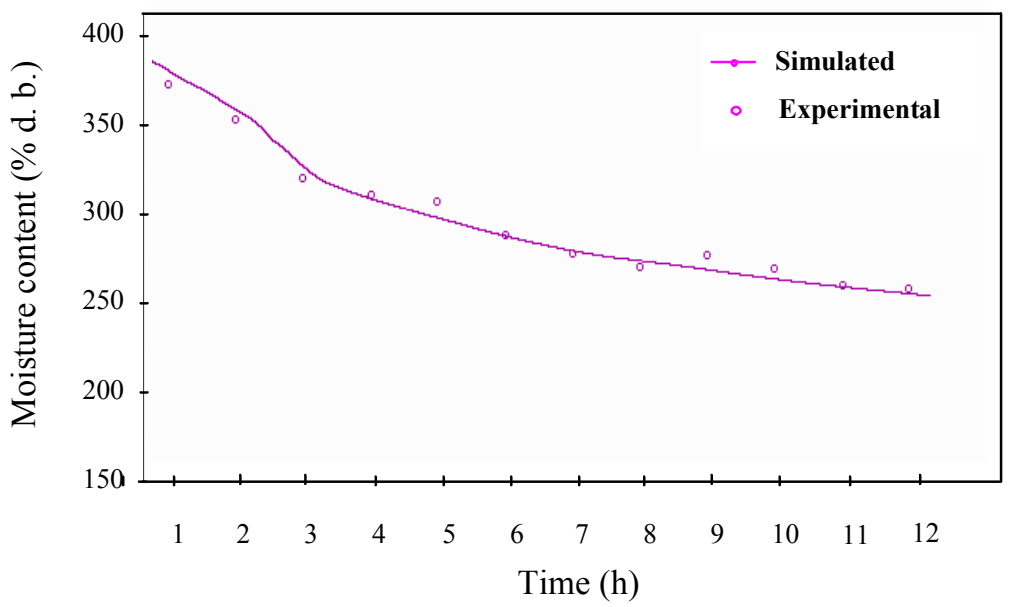

Fig. 6. Average experimental and simulated moisture contents of tea leaves of the experiments (I) and (III)

The latent heat of vaporization increases exponentially since water is bound tightly at lower moisture contents. Temperature and $\mathrm{RH}$ of air entering to the withering trough were measured using the data acquisition system and the variation of the parameters with time is given in Fig. 5. The average moisture contents of tea leaves drawn at one hour interval were compared with the model calculated average moisture content for $12 \mathrm{~h}$ withering (Fig. 6). Statistical criteria to evaluate the correlation of experimental and simulated curves are given in Table 1. The statistical data of average moisture contents of tea leaves on wet basis were calculated by the QBASIC program. Average moisture content of observed data showed a good agreement with the simulated data with standard error (SEE) in the range of 0.6248 1.2319 and mean relative deviation $(P)$ in the range of $0.6742-1.4950$ on percent wet basis. Experimental moisture contents of top, middle and bottom layers of leaves were also had a close agreement with the simulated data with SEE in the range of $0.2940-1.2872,0.7148$ 1.1025 and $0.7106-4.5478$ and $P$ in the range of $0.2820-1.4548,0.8022-1.2955$ and $2.8983-$ 5.8681 , respectively on per cent wet basis (Table 2). 
Table 1. Standard error and mean relative deviation of average moisture content of tea leaves

\begin{tabular}{lcc}
\hline Experiment No & SEE & $\boldsymbol{P ( \% )}$ \\
\hline Exp 1 & 0.6248 & 0.6742 \\
Exp 2 & 1.0581 & 1.3121 \\
Exp 3 & 1.2319 & 1.4950 \\
Exp 4 & 0.4797 & 0.5241 \\
\hline
\end{tabular}

Table 2. Statistical parameters used to evaluate the moisture content in different layers of leaves

\begin{tabular}{llcl}
\hline Experiment No & Layer & SEE & P (\%) \\
\hline 1 & Top & 0.5709 & 0.5772 \\
& Middle & 1.1025 & 1.2955 \\
& Bottom & 2.2245 & 2.8983 \\
2 & Top & 1.2872 & 1.4548 \\
& Middle & 0.8540 & 0.9637 \\
3 & Bottom & 4.5478 & 5.8681 \\
& Top & 0.2940 & 0.2820 \\
& Middle & 0.7232 & 0.8022 \\
4 & Bottom & 3.3450 & 4.7523 \\
& Top & 0.4300 & 0.4693 \\
& Middle & 0.7148 & 0.8760 \\
& Bottom & 0.7106 & 0.6657 \\
\hline
\end{tabular}

Figure 7 demonstrates the variation of experimental and simulated moisture contents of tea leaves on top, middle and bottom layers of the leaf bed. A deviation of the simulated curves was noticed in the graph of bottom layer at the latter stage of the withering process. Experimental moisture was higher than simulated value of the bottom layer of the leaves. This deviation is due to packing of the leaves at the bottom layer at the latter stage of withering. It withers comparatively a faster rate than other two layers. Very slight deviations were observed for the top and middle layers. It shows higher moisture content in predicted data than the experimental data at the latter stage of withering. Sampling errors due to narrowing the layer thickness at the latter stage may cause to this deviation.

Top layer

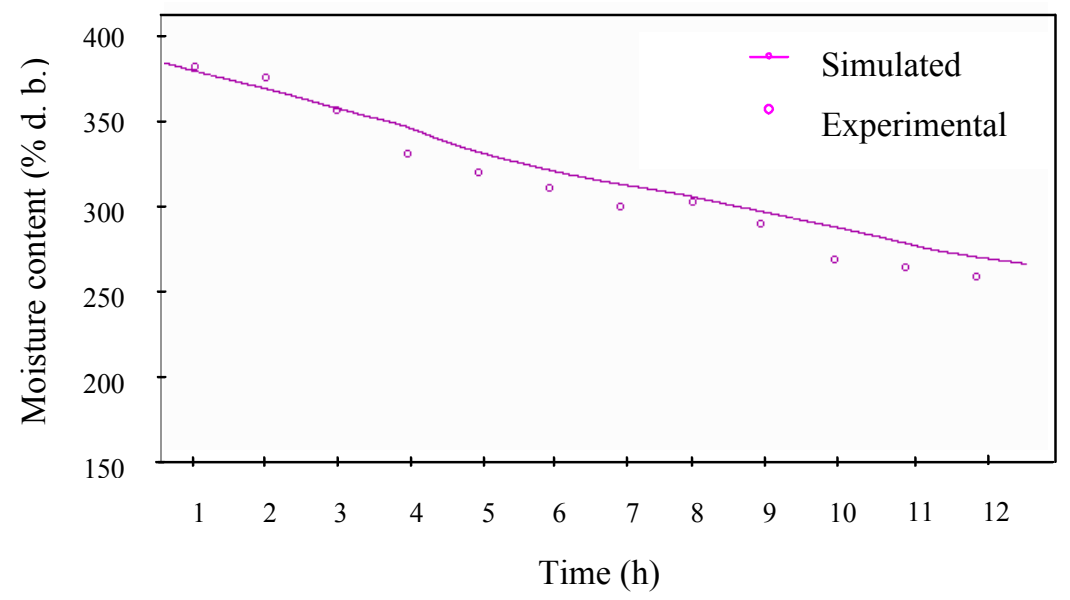




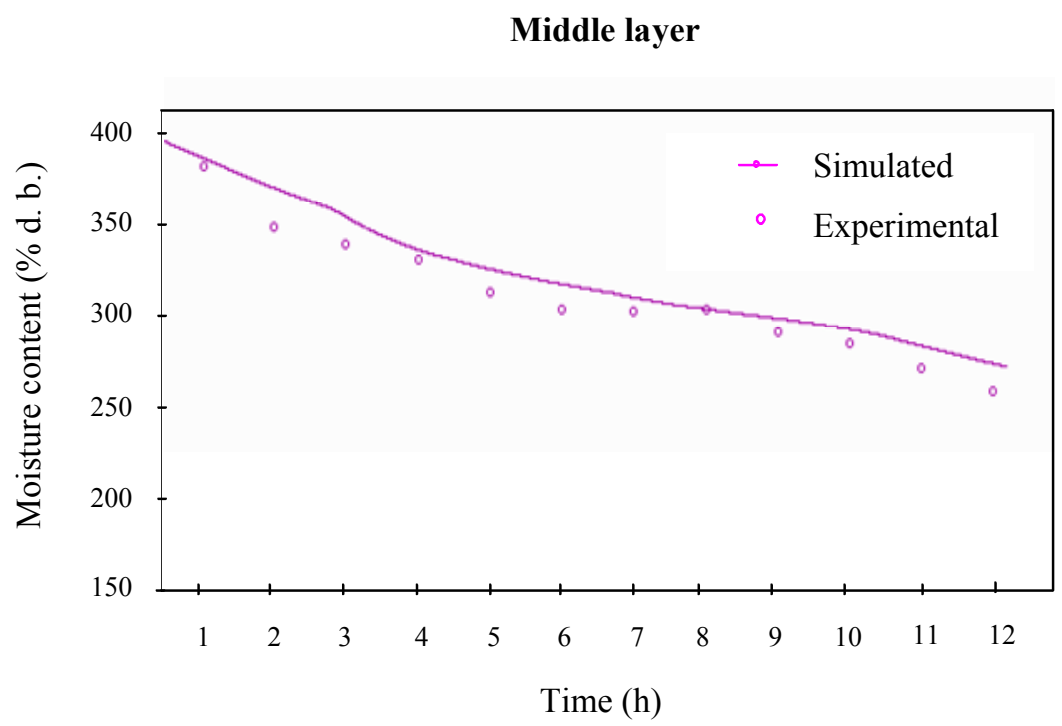

Bottom layer

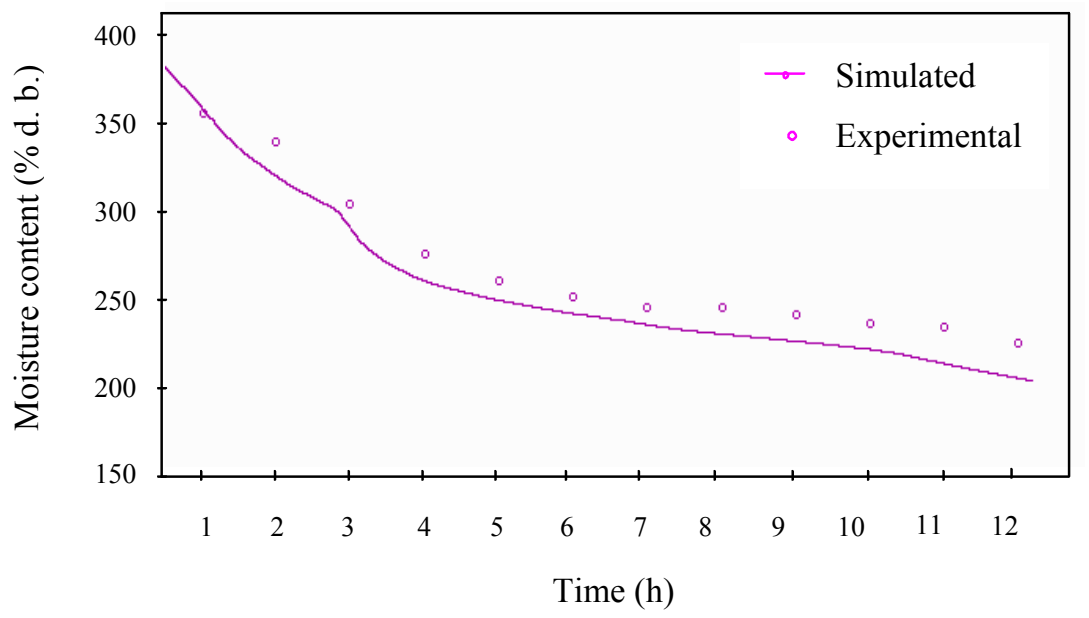

Fig. 7. Experimental and simulated moisture contents from top to bottom layers in experiment (I)

\section{CONCLUSIONS}

One-dimensional heat and mass transfer model was developed to simulate the real time moisture content of tea leaves in trough withering. A commercial type of withering trough was used to validate the developed model. Results showed that the model calculated moisture data were in close agreement with the experimental data. Average moisture content of experimental data showed in range of $0.6248-1.2319 \%$ standard error (SEE) on wet basis as against the simulated moisture data. 


\section{REFERENCES}

Bolton, D. (1980). The computation of equivalent potential temperature. Monthly Weather Review. 108(7), 1046-1053.

Botheju, W. S., Amaratunga, K. S. P. and Abeysinghe, I. S. B. (2008). Thin layer drying characteristics of fresh tea leaves. Proceedings of the $2^{\text {nd }}$ symposium on plantation crop research, BMICH, Colombo, Sri Lanka, 10-19.

Botheju, W. S. (2009). Heat transfer coefficient of fresh tea leaves. Ph.D. thesis. Moisture simulation of tea leaves in trough withering using finite element heat and mass transfer model, p. 110.

Cengel, Y.A. and Boles, M. A. (1989). Molar mass, gas constant and critical-point properties. In "Thermodynamics and Engineering Approach, $2^{\text {nd }}$ edition, McGraw-Hill, $p$. 868.

ISO 1568 (1980). Tea-Determination of loss in mass at $103^{\circ} \mathrm{C}$. International Standard Organization Second Edition 1573-1980, Switzerland.

Mohamed, M. T. Z., Raveendran, K., Botheju, W S., Priyanthi, S. H., and Jayasinghe, L., (2003). A rapid method to determine moisture content in green leaf, withered leaves and made tea using a microwave oven. Sri Lankan J. Tea Sci. 68(2), 44-48.

Morey, R. V., Keener, H. M., Thompson, T. L., White, G. M. and Bakker-Arkema, F. W. (1978). The present state of grain drying simulation. ASAE Paper No. 78-3009.

Muir, W. E., Fraser, M., and Sinha, R. N., (1980). Simulation model of two dimensional heat and mass transfer in controlled-atmosphere grain bins. In Controlled Atmosphere Storage Grain. J. Shejbal (Ed.), Amsterdam, Elsevier Scientific Publication Co. pp. 385-398.

Murata, S., Amaratunga, K. S. P., Tanaka, F., Shibuya, K. and Koide, S. (1996). Simulation of moisture adsorption by polished rice in deep-bed. Food Sci. \& Tech. Inst. 2(2), 86-91.

Samaraweera, D. S. A., (1986). Technology of tea processing. Handbook on Tea. Sivapalan, P., Kulasegaram, S. and Kathiravetpillai, A. (Eds.).Tea Research Institute of Sri Lanka. pp. 158-207.

Siebel, J. F. (1892). Specific heat of various products. Ice Refrigeration, 2, 256-257.

Yaciuk, G., Muir, W E, Fraser, M., and Sinha, R. N. (1975). A simulation model of temperatures in stored grain. J. of Agric. Eng. Res., 20, 245-258.

\section{Abbreviations used}

$C_{\mathrm{ps}} \quad$ Specific heat capacity of tea leaves $(\mathrm{kJ} / \mathrm{kg} . \mathrm{K})$

$C_{\mathrm{pa}} \quad$ Specific heat capacity of air $(\mathrm{kJ} / \mathrm{kg} . \mathrm{K})$

$C_{\mathrm{pw}} \quad$ Specific heat capacity of wet air $(\mathrm{kJ} / \mathrm{kg} . \mathrm{K})$

d.b. Dry basis

$G \quad$ Mass velocity of air per unit bed area $\left(\mathrm{kg} / \mathrm{s} \mathrm{m}^{2}\right)$

$h_{a} \quad$ Heat transfer coefficient of tea leaves $\left(\mathrm{kJ} / \mathrm{s} . \mathrm{m}^{2} . \mathrm{K}\right)$ 
$h \quad$ Equilibrium relative humidity (decimal)

I Enthalpy of air $(\mathrm{kJ} / \mathrm{kg})$

$i \quad$ Layer number

$j \quad$ Number of times air temperature and $\mathrm{RH}$ read

$k \quad$ Drying constant / coefficient $\left(\mathrm{s}^{-1}\right)$

$M_{e} \quad$ Equilibrium moisture content (\% d.b.)

$M \quad$ Moisture content of tea leaves at given time (\% d.b.)

$M_{d(w b)} \quad$ Moisture content of tea leaves in decimal wet basis

$P_{s} \quad$ Saturated vapor pressure of water $(\mathrm{kPa})$

$P_{s t} \quad$ Vapor pressure of water in tea leaves $(\mathrm{kPa})$

$p \quad$ Vapor pressure $(\mathrm{kPa})$

$q \quad$ Latent heat of evaporation of tea leaves $(\mathrm{kJ} / \mathrm{kg})$

$R_{w} \quad$ Gas constant of water vapor $(\mathrm{kJ} / \mathrm{kg} \mathrm{K})$

rh Relative humidity (decimal)

$T \quad$ Absolute temperature (K)

$T_{a} \quad$ Air temperature (K)

$T_{\mathrm{c}} \quad$ Temperature $\left({ }^{\circ} \mathrm{C}\right)$

$T_{\mathrm{s}} \quad$ Temperature of tea leaves $(\mathrm{K})$

$t \quad$ Time (s)

$V_{\mathrm{g}}, V_{1} \quad$ Specific volume of water vapor and liquid water at given temperature $\left(\mathrm{m}^{3} / \mathrm{kg}\right)$

$V \quad$ Volume flow rate $\left(\mathrm{m}^{3} / \mathrm{sec}\right)$

w.b. Wet basis

$X \quad$ Absolute humidity ( $\mathrm{kg}$ water $/ \mathrm{kg}$ of dry air)

$y \quad$ Layer thickness

$\rho_{\mathrm{s}} \quad$ Bulk density of tea leaves $\left(\mathrm{kg} / \mathrm{m}^{3}\right)$

$\rho_{\mathrm{a}} \quad$ Density of air $\left(\mathrm{kg} / \mathrm{m}^{3}\right)$

$\sigma \quad$ Latent heat of vaporization of water $(\mathrm{kJ} / \mathrm{kg})$

$\Delta l \quad$ Element thickness (m)

$\Delta t \quad$ Time increment (s) 